\title{
A Case of a Cholesterol Granuloma Occluding the External Auditory Canal in a 12-Year-Old Girl
}

\author{
Ji Sun Kong ${ }^{1}$, Mee-Seon Kim², and Kyu-Yup Lee ${ }^{1}$ \\ ${ }^{1}$ Departments of Otorhinolaryngology-Head and Neck Surgery, ${ }^{2}$ Pathology, School of Medicine, Kyungpook National University, \\ Daegu, Korea
}

Received March 11, 2014

Revised June 15, 2014

Accepted June 25, 2014

Address for correspondence

Kyu-Yup Lee, MD, PhD

Department of Otorhinolaryngology-

Head and Neck Surgery,

School of Medicine,

Kyungpook National University,

130 Dongdeok-ro, Jung-gu,

Daegu 700-721, Korea

Tel $+82-53-420-5756$

Fax +82-53-423-4524

E-mail kylee@knu.ac.kr
Cholesterol granulomas are benign granulomatous lesions caused by tissue reaction to a foreign body such as cholesterol crystals. These crystals have been are associated with pathological conditions of pneumatized spaces, including those causing inadequate aeration, obstruction of drainage, and hemorrhage in pneumatized spaces, and where materials trapping materials, such as hemosiderin or cholesterol become trapped, and then forming a cholesterol granuloma. Cholesterol granulomas are frequently found in the temporal bones, with the middle ear, mastoid caverna, and petrous apex being the most commonly affected sites. As there have been few reported cases of cholesterol granulomas presenting as a mass in the external acoustic canal (EAC), a cholesterol granuloma occluding the entire EAC in a pediatric patient is considered quite rare. We encountered a large cholesterol granuloma occupying the entire EAC, resulting in total EAC occlusion in a 12-year-old girl. The granuloma was diagnosed via medical imaging and surgically excised.

Korean J Audiol 2014;18(2):89-92

KEY WORDS: Cholesterol granuloma · Children · External auditory canal.

\section{Introduction}

Acquired external auditory canal (EAC) stenosis is relatively rare and results from infection, inflammation, trauma, and tumors. The incidence of acquired EAC stenosis has been estimated at 0.6 cases per 100000 people. ${ }^{1)}$ Chronic otitis externa is the most common cause of acquired EAC stenosis. ${ }^{2)} \mathrm{Neo-}$ plasms such as bony exostosis, benign inflammatory tumors, and malignant lesions can also cause EAC occlusion. Cholesterol granulomas are benign granulomatous lesions caused by tissue reaction to a foreign body. The lesion formation is caused by cholesterol crystals, and occurs secondary to insufficient ventilation, drainage disorders, hemorrhage, and/or chronic inflammation. ${ }^{3)}$ This process was first described by Manasse ${ }^{4)}$ in 1894. These lesions have been reported in various regions of the body where cholesterol crystals may form such as the lungs, breasts, peritoneum, mediastinum, liver, spleen, thyroid, kidneys, lymph nodes, testis, facial skeleton, skull, and the tem-

This is an Open Access article distributed under the terms of the Creative Commons Attribution Non-Commercial License (http://creativecommons. org/licenses/by-nc/3.0/) which permits unrestricted non-commercial use, distribution, and reproduction in any medium, provided the original work is properly cited. poral bones. ${ }^{5-8)}$ Within the temporal bones, cholesterol granuloma is known to occur most commonly in the petrous apex., ${ }^{9,10}$ With few cases of cholesterol granuloma presenting as a mass in the EAC having been reported, occlusion of the entire EAC by a cholesterol granuloma in a pediatric patient is quite rare. ${ }^{9-11)}$ A pre-operative diagnosis of the EAC-occluding mass is necessary to devise appropriate treatment, reduce operative complications, reduce post-operative morbidity, and effectively restore hearing. Correct diagnosis of EAC stenosis is challenging in young children owing to the low incidence of EAC masses in the pediatric population. Here, we report a large cholesterol granuloma occupying the entire EAC and resulting in its total occlusion in a 12-year-old girl. The granuloma was diagnosed via medical imaging and surgically excised.

\section{Case Report}

A 12-year-old girl presented with progressive hearing loss in the right ear and was referred to our hospital. The patient complained of progressive hearing impairment and fullness of the right ear. She had no history of otitis media or previous trauma to the ear. On physical examination, the right tympan- 
ic membrane was not visible because of a mass that was completely obstructing the EAC. Right-sided hearing measured using pure tone audiometry was $55 \mathrm{~dB}$ hearing level, with an air-bone gap of $45 \mathrm{~dB}$, demonstrating moderate, conductive hearing loss (Fig. 1). The patient had a normal hearing threshold in the left ear. High-resolution computed tomography (CT) revealed a large, soft-tissue mass located in the right temporal bone measuring $4.0 \times 3.3 \mathrm{~cm}$ in size with clearly defined boundaries. The mass filled the right EAC and had eroded the lateral part of the EAC and the mastoid cortex. The mass did not involve the tympanic membrane, middle ear, ossicles, or mastoid antrum (Fig. 2). In order to better characterize the lesion, magnetic resonance imaging (MRI) was performed. MRI revealed a mass with high signal intensity in T1- and T2-weighted images. Contrast-enhanced, T1-weighted images revealed a non-enhanced mass with high signal intensity (Fig. 3).

Based on the diagnosis of a cholesterol granuloma from the results of medical imaging, surgery under general anesthesia was performed via a postauricular approach. A cystic mass containing a sticky, brown-colored liquid was located just below the subcutaneous tissue and was discovered to have eroded the mastoid cortex at the posterior and superior portions of the lateral EAC (Fig. 4A). The mass had extended near to the tympanic membrane and superficial mastoid air cell but not into the mastoid antrum or middle ear. After the mass was completely excised (Fig. 4B), the widened EAC and exposed mastoid air cells were covered with a posterior-based periosteal flap, and the skin of the EAC was repositioned. There were no post-operative complications such as infection, bleeding, or facial palsy. Histopathological analysis of the mass revealed a typical cholesterol granuloma with numerous cholesterol clefts surrounded by immature, fibrous tissue. The mass was also described as having an abundance of polynuclear cells, giant cells, and round cells (Fig. 5A).

Post-operatively, the child's hearing was restored to the threshold of $10 \mathrm{~dB}$ in the right ear (Fig. 6). At 2 years after sur- gery, there were no postoperative complications, nor was there recurrence or EAC stenosis (Fig. 5B).

\section{Discussion}

Cholesterol granuloma is a histological term used to describe a tissue response to a foreign body such as cholesterol crystals. It has been suggested that the major causes of cholesterol granuloma are related to a number of diverse middle ear diseases: insufficient ventilation, obstruction of drainage, hemorrhage into pneumatized spaces, and chronic inflammation. ${ }^{8)}$ When a ventilation problem occurs, edema of the mucous membranes and rupture of a blood vessel may result secondary to the negative pressure created in the closed space. The degradation products of hemoglobin may then be exposed to the surrounding tissue, causing a foreign-substance reaction. ${ }^{8)}$ Upon repetition of the inflammatory reaction and additional hemorrhage, a cholesterol granuloma can form. In our patient, a cholesterol
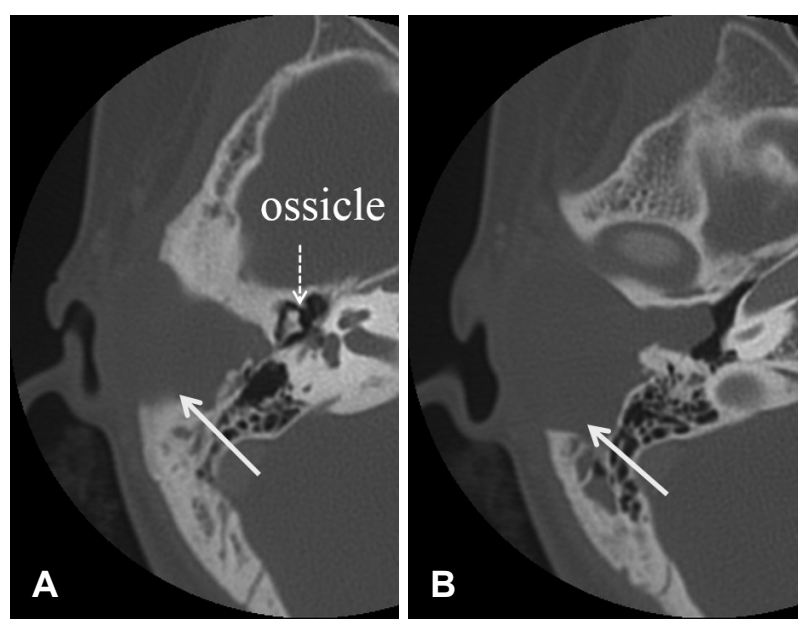

Fig. 2. A pre-operative temporal bone CT scans show a large, wellcircumscribed, iso-dense mass (arrow) filling the right external auditory canal, eroding the mastoid cortex, and extending into the temporal bone. A: Attic level at axial view. B: The external auditory canal level at axial view.

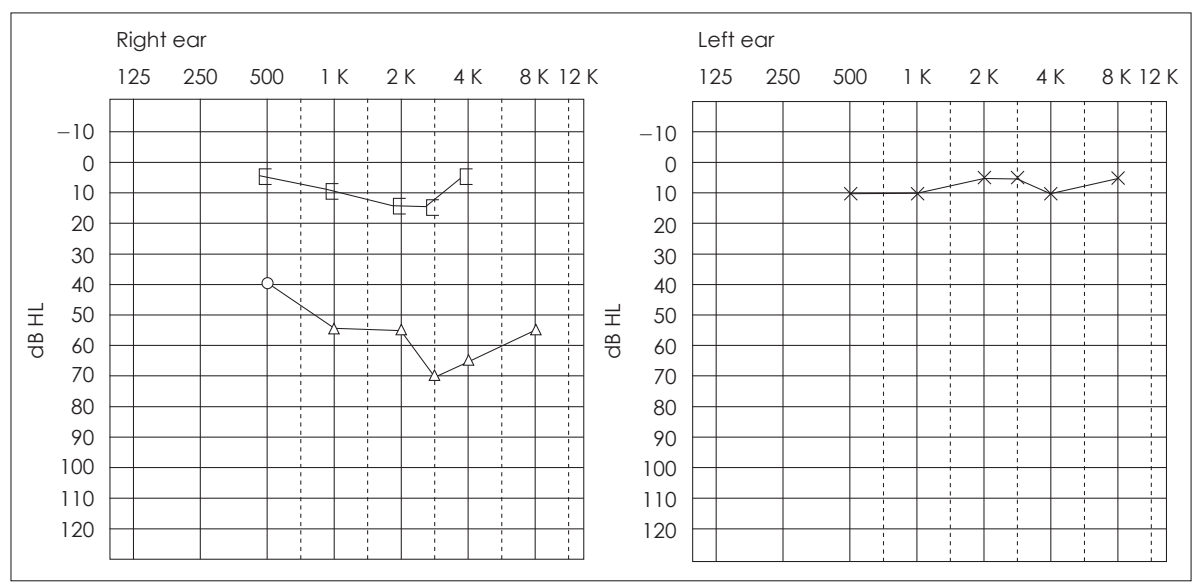

Fig. 1. Pre-operative pure tone audiometry (PTA). The pre-operative PTA average was $55 \mathrm{~dB} \mathrm{HL}$ with an airbone gap of $45 \mathrm{~dB} \mathrm{HL}$, showing moderate conductive hearing loss in the right ear. The patient had a normal hearing threshold in the left ear. 
granuloma formed a large mass in the EAC involving the lateral aspect of the temporal bone, which appears to support the local hemorrhage theory proposed by Friedmann. ${ }^{12)}$ The lesion may have originated inside of the tympanic bone of the EAC, and expanded to the mastoid and EAC.

A cholesterol granuloma presenting as a mass and causing total stenosis of the EAC in a young child is quite rare. When a well-marginated, isodense mass obstructing the EAC with

Fig. 3. Pre-operative magnetic resonance (MR) images. T1- (A) and T2weighted MR images $(B)$ show a wellcircumscribed cystic mass (arrow) with high signal intensity. The contrast-enhanced, T1-weighted image shows a non-enhanced mass with high signal intensity (C).
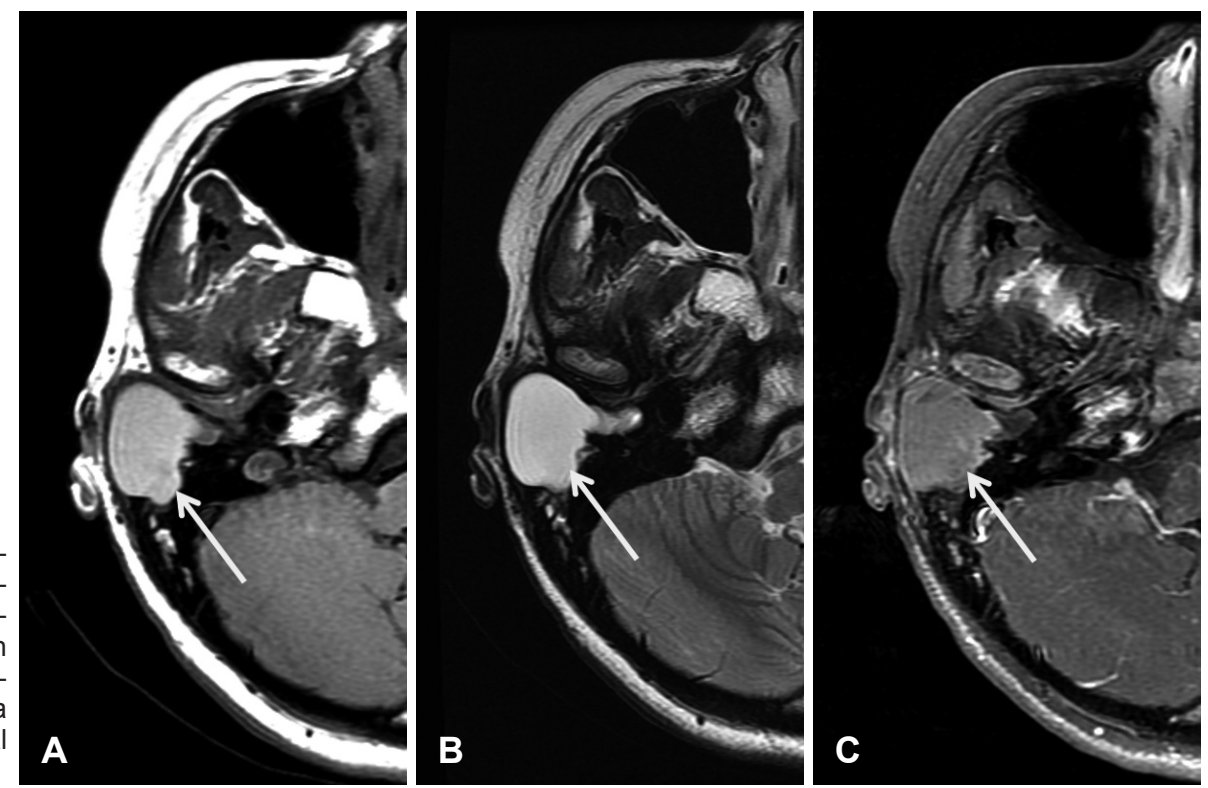

Fig. 4. Intra-operative findings. The cholesterol granuloma are exposed via a postauricular approach (A). After the tumor was completely removed, the tympanic membrane (asterisk), the widened external auditory canal, and eroded mastoid bone were seen $(B)$.
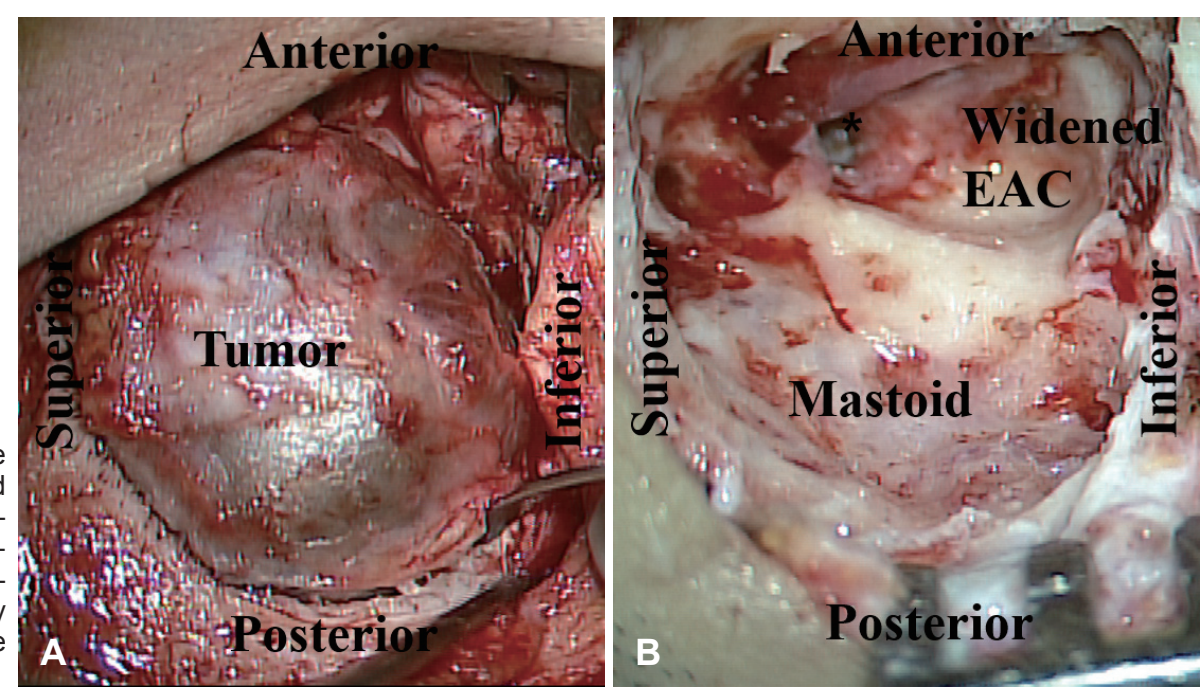

Fig. 5. A: Pathological findings show fusiform clefts created by cholesterol crystals that have been dissolved during processing. Many cholesterol crystals are engulfed by multi-nucleated giant cells $(H \& E$ stain, $\times 200)$. B: The post-operative right eardrum 24 months after the surgery observed through the patent external auditory canal.
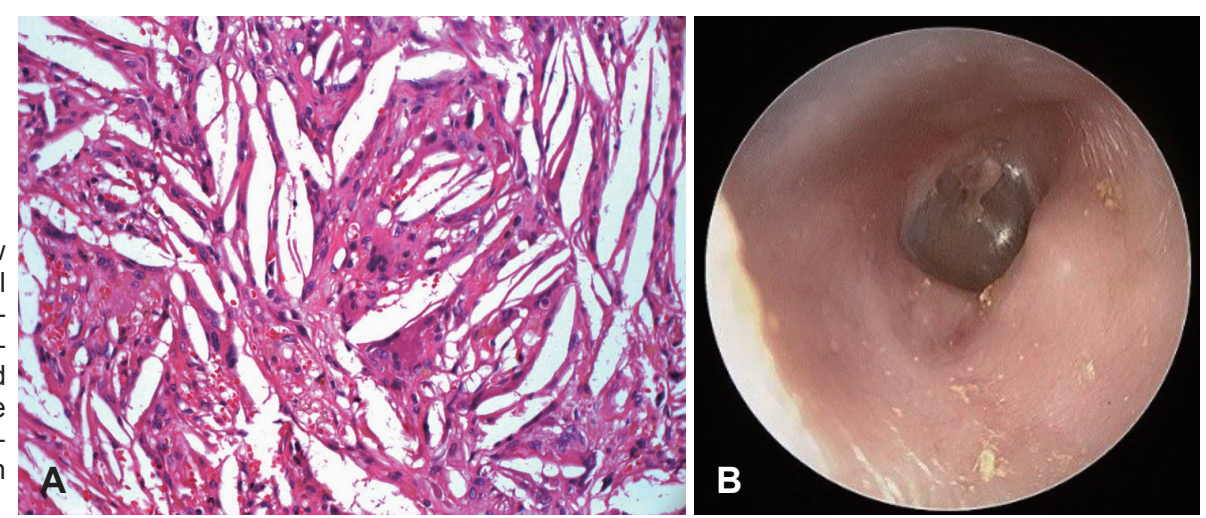


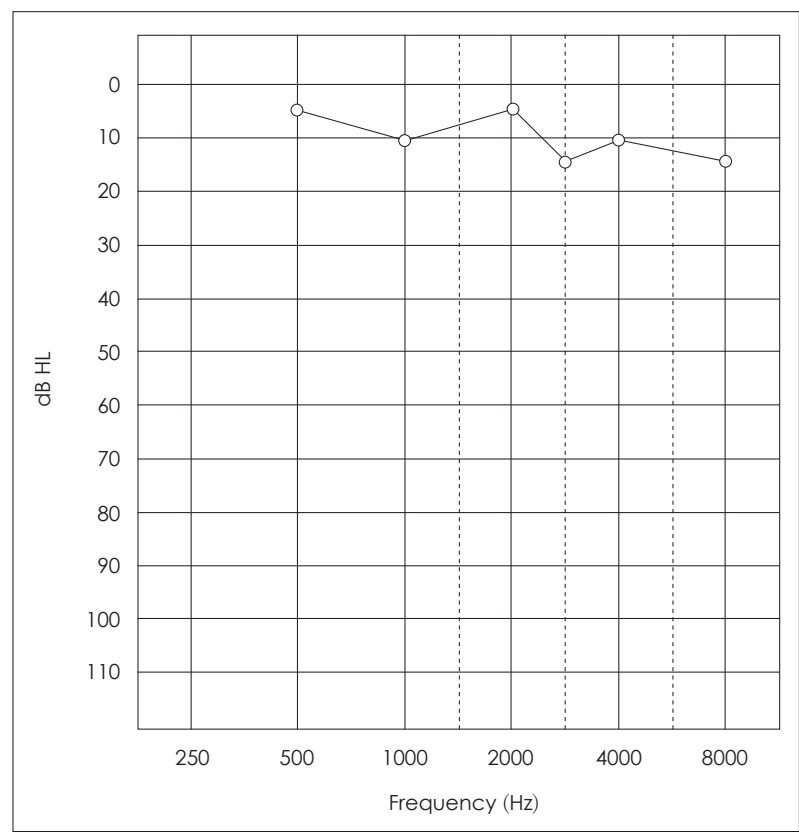

Fig. 6. Post-operative pure tone audiometry (PTA) 24 months after surgery. Post-operative PTA demonstrates a normal hearing threshold in the right ear.

an eroded mastoid cortex and no middle ear or mastoid antrum involvement was revealed on $\mathrm{CT}$, the following conditions were considered in the differential diagnosis: a cholesteatoma, otitis externa, or a rare neoplasm of the temporal bone, including a malignant or benign tumor such as a mucinous cyst or a branchial cleft cyst. Additionally, MRI imaging showed high signal intensity on both the T1- and T2-weighted images, and there was no gadolinium enhancement to suggest a cholesterol granuloma. Diagnostic imaging including CT and MRI are essential in establishing the appropriate diagnosis and treatment plan for a cholesterol granuloma. It should be noted that the pathognomonic MRI findings for a cholesterol granuloma consist of high signal intensity on both T1- and T2-weighted images due to cholesterol crystals and hemoglobin degradation products. $^{13)}$

Cholesterol granulomas do not routinely require surgery. However, surgical intervention may be considered based on the size and location of the lesion, the existence of symptoms, and the necessity for diagnostic confirmation. ${ }^{14,15)}$ In this case, the mass was excised through limited mastoidectomy, and the widened EAC and opened mastoid air cells were covered with a posterior-based periosteal flap. As a result of surgical intervention, the patency of the EAC was maintained without the post-operative complications of necrosis or stenosis.

A cholesterol granuloma occluding the EAC in a young child is quite rare. The authors of this case report a rare large cholesterol granuloma in the EAC of a 12-year-old child that was diagnosed by pre-operative CT and MRI scans, surgically removed, and reconstruction performed without any complications. Normal hearing was restored after surgery. Even in rare diseases, patients can be treated safely through proper diagnosis and appropriate treatment.

\section{REFERENCES}

1) Becker BC, Tos M. Postinflammatory acquired atresia of the external auditory canal: treatment and results of surgery over 27 years. Laryngoscope 1998;108:903-7.

2) Luong A, Roland PS. Acquired external auditory canal stenosis: assessment and management. Curr Opin Otolaryngol Head Neck Surg 2005;13:273-6.

3) Nager GT, Vanderveen TS. Cholesterol granuloma involving the temporal bone. Ann Otol Rhinol Laryngol 1976;85(2 pt.1):204-9.

4) Manasse P. Uber granulationsge schwulste mit fremdkorperrisenzellen. Virchows Arch 1894;136:245.

5) Luckraz H, Coulston J, Azzu A. Cholesterol granuloma of the superior mediastinum. Ann Thorac Surg 2006;81:1509-10.

6) Gunes HA, Almac A, Canbay E. Cholesterol granuloma of the maxillary antrum. J Laryngol Otol 1988;102:630-2.

7) Rinaldo A, Ferlito A, Cureoglu S, Devaney KO, Schachern PA, Paparella MM. Cholesterol granuloma of the temporal bone: a pathologic designation or a clinical diagnosis? Acta Otolaryngol 2005;125: 86-90.

8) Royer MC, Pensak ML. Cholesterol granulomas. Curr Opin Otolaryngol Head Neck Surg 2007;15:319-22.

9) Nikolaidis V, Malliari H, Psifidis D, Metaxas S. Cholesterol granuloma presenting as a mass obstructing the external ear canal. BMC Ear Nose Throat Disord 2010;10:4.

10) Shoman NM, Samy RN, Pensak ML. Double-barrel stenting in infracochlear approach for drainage of petroux apex cholesterol granulomas. Laryngoscope 2011;121:574-6.

11) Matt BH, Myer CM 3rd, Bellet PS. Cholesterol granuloma presenting in the ear canal. Ann Otol Rhinol Laryngol 1990;99:672-3.

12) Friedmann I. Pathology of the ear. Oxford: Blackwell Scientific;1974.

13) Goldofsky E, Hoffman RA, Holliday RA, Cohen NL. Cholesterol cysts of the temporal bone: diagnosis and treatment. Ann Otol Rhinol Laryngol 1991;100:181-7.

14) Shih TY, Prendes BL, Parsa AT, Cheung SW. Erosive cholesterol granuloma. Otol Neurotol 2013;34:e26-7.

15) Shihada R, Brand R, Segev Y, Luntz M. Spontaneous regression of petrous apex cholesterol granuloma. Otol Neurotol 2012;33:e9-10. 